\title{
In vitro and in vivo effects of standardized extract and fractions of Phaleria macrocarpa fruits pericarp on lead carbohydrate digesting enzymes
}

\author{
Rabyah B Ali ${ }^{1}$, Item J Atangwho ${ }^{1,2^{*}}$, Navneet Kuar ${ }^{1}$, Mariam Ahmad ${ }^{1}$, Roziahanim Mahmud ${ }^{1}$ and Mohd Z Asmawi ${ }^{1 *}$
}

\begin{abstract}
Background: One vital therapeutic approach for the treatment of type 2 diabetes mellitus is the use of agents that can decrease postprandial hyperglycaemia by inhibiting carbohydrate digesting enzymes. The present study investigated the effects of bioassay-guided extract and fractions of the dried fruit pericarp of Phaleria macrocarpa, a traditional anti-diabetic plant, on a-glucosidase and a-amylase, in a bid to understand their anti-diabetic mechanism, as well as their possible attenuation action on postprandial glucose increase.

Methods: Methanol extract (ME), obtained by successive solvent extraction, its most effective liquid-liquid n-butanol fraction (NBF) and the flash column chromatographic sub-fraction (SFI), were evaluated for in vitro a-glucosidase (yeast) and a-amylase (porcine) activity inhibition. Furthermore, confirmatory in vivo tests were carried out in streptozotocin-induced diabetic rats (SDRs) using oral glucose, sucrose and starch tolerance tests.

Results: At the highest concentration employed $(100 \mu \mathrm{g} / \mathrm{ml})$, NBF showed highest inhibition against a-glucosidase (75\%) and a-amylase (87\%) in vitro $\left(\mathrm{IC}_{50}=2.40 \pm 0.23 \mu \mathrm{g} / \mathrm{ml}\right.$ and $58.50 \pm 0.13 \mu \mathrm{g} / \mathrm{ml}$, respectively) in a dose-dependent fashion; an effect found to be about 20\% higher than acarbose (55\%), a standard a-glucosidase inhibitor $\left(\mathrm{IC}_{50}=3.45 \pm\right.$ $0.19 \mu \mathrm{g} / \mathrm{ml})$. The ME and SFI also inhibited a-glucosidase $\left(\mathrm{C}_{50}=7.50 \pm 0.15 \mu \mathrm{g} / \mathrm{ml}\right.$ and $\left.11.45 \pm 0.28 \mu \mathrm{g} / \mathrm{ml}\right)$ and a-amylase $\left(I C_{50}=43.90 \pm 0.19 \mu \mathrm{g} / \mathrm{ml}\right.$ and $\left.69.80 \pm 0.25 \mu \mathrm{g} / \mathrm{ml}\right)$, but to a lesser extent. In in vivo studies with diabetic rats, NBF and SFI effectively reduced peak blood glucose (PBG) by $15.08 \%$ and $6.46 \%$, and the area under the tolerance curve (AUC) by $14.23 \%$ and $12.46 \%$, respectively, after an oral sucrose challenge $(P<0.05)$; thereby validating the observed in vitro action. These reduction effects on PBG and AUC were also demonstrated in glucose and starch tolerance tests, but to a lesser degree.
\end{abstract}

Conclusions: These findings reveal that P. macrocarpa can attenuate hyperglycaemia in both in vitro and in vivo conditions by potently inhibiting carbohydrate hydrolysing enzymes, making it a viable plant for sourcing natural compounds for the management of type 2 diabetes mellitus.

Keywords: a-Glucosidase, a-Amylase, Peak blood glucose, Postprandial hyperglycaemia, Type 2 diabetes mellitus, Phaleria macrocarpa

\footnotetext{
* Correspondence: dratangwho@gmail.com; amzaini@usm.my

${ }^{1}$ School of Pharmaceutical Sciences, Universiti Sains Malaysia, Minden 11800 Penang, Malaysia

2Department of Biochemistry, College of Medical Sciences, University of Calabar, P. M. B. 1115, Calabar, Nigeria
}

\section{CiolMed Central}

(c) 2013 Ali et al.; licensee BioMed Central Ltd. This is an Open Access article distributed under the terms of the Creative Commons Attribution License (http://creativecommons.org/licenses/by/2.0), which permits unrestricted use, distribution, and reproduction in any medium, provided the original work is properly cited. 


\section{Background}

Plants have been exemplary sources of medicine since ancient times. They have played key roles in traditional health care systems and on the basis of this, have become a significant percentage of allopathic and modern drugs in many nations of the world [1,2]. Medicinal plants are therefore used as modern alternatives to orthodox medicines or as complementary products to maintain health or treat aspects of diseases, particularly where conventional medication has had only limited success [3].

Diabetes is one such disease that has been managed with only limited success by "Western" medicine. Conventional effort at better management of diabetes has been disappointing and the control of blood glucose level remains unsatisfactory, as reflected in daily increases in morbidity and mortality rates [4]. Consequently, the current focus for appropriate anti-diabetic agents is herbal medicine. There is, however, a need for more in-depth investigation to confirm and advocate the benefits of these plants over existing therapies, including elucidation of their mechanism(s) of action and therapeutic effects, as the anti-diabetic evidence is often anecdotal [5].

Phaleria macrocarpa (Scheff) Boerl (Thymelaceae), a shrub known locally as Mahkota Dewa, literally translated as "God's Crown", has for centuries been used by the native Indonesians and the lower course of Malaysia to combat diabetes, liver diseases, vascular problems, cancer, and high blood pressure [6]. The parts of P. macrocarpa that are used for medicinal treatments are the stems, leaves and fruits. Although the works of Triastu and Choi [7] and Triastu et al. [8] on oxidative stress protection in alloxan diabetes suggest scientific validation of its anti-diabetic activity, there are no reports, to our knowledge, on the detailed anti-diabetic mechanism of $P$. macrocarpa. Earlier exploratory studies with young and old fruit extracts of $P$. macrocarpa on non-diabetic rats [9], and later with young and old leaf extracts [10] suggested that P. macrocarpa possessed possible $\alpha$-glucosidase inhibitory activity.

It was therefore necessary to conduct a detailed study with the aim to understand at least in part, the antidiabetic mechanism of $P$. macrocarpa as it relates to inhibition of carbohydrate hydrolysis since drugs with this property can circumvent postprandial hyperglycaemic risk in diabetes. In vitro studies are relatively simple, precise and most suitable when a large number of compounds or fractions are to be tested, and are also used in mechanistic elucidation [11]. However, a confirmatory in vivo test is also necessary to substantiate positive in vitro results, since positive $\alpha$-glucosidase inhibitory action may not always correlate with in vivo actions [12]. Accordingly, the present study employed both in vitro and in vivo test procedures to evaluate the effect of $P$. macrocarpa on carbohydrate digesting enzymes. Moreover, the studies also followed a systematized drug discovery program of bioassay-guided extraction and test procedures. An activity-guided approach is indispensable in natural product discovery or standardization of herbal products for use as alternatives and/or complements to conventional medicines.

The present study evaluated the in vitro inhibition of yeast $\alpha$-glucosidase (EC 3.2.1.20) and porcine pancreatic $\alpha$-amylase (EC 3.2.1.1) activities of the active crude extract, fraction and sub-fraction of $P$. macrocarpa identified earlier from activity-guided hypoglycaemic and anti-hyperglycaemic tests carried out in our laboratory $[13,14]$. A confirmatory in vivo study was also conducted in non-diabetic and streptozotocin-induced diabetic rats.

\section{Methods}

\section{Preparation of plant extracts and fractions}

Fruits of Phaleria macrocarpa were collected from Kepala Batas, Seberang Perai, Pulau Pinang, Malaysia in August, 2010. They were identified by Mr. V. Shunmugam a/l Vellosamy and a voucher specimen of the plant (voucher number 11259) was deposited in the herbarium unit, School of Biological Sciences, Universiti Sains Malaysia. The pericarps of the fruits were sliced, dried, and powdered using a milling machine. About $2,400 \mathrm{~g}$ were successively extracted with petroleum ether and methanol using Soxhlet apparatus $\left(40^{\circ} \mathrm{C}\right)$ for $48 \mathrm{~h}$ each. Thereafter, the residue from the methanol extraction after complete drying was extracted with water by maceration at $60^{\circ} \mathrm{C}$ for 24 hours. Extraction with each solvent was done in triplicate and the extracts obtained were filtered with Whatman No. 1 filter paper and concentrated in vacuo by rotary evaporation (Buchi Labortechnik, Flawil, Switzerland). The concentrated extracts were finally lyophilized to obtain $73.6 \mathrm{~g}$ (3.06\%), $445.36 \mathrm{~g}$ (18.55\%) and $146 \mathrm{~g}$ (6.08\%) each of dried petroleum ether extract (PEE), methanol extract (ME) and water extract (WE), respectively. Earlier results from hypoglycaemic and anti-hyperglycaemic tests with these extracts showed that the methanol extract was the most effective in lowering blood glucose [13], and thus this alone was used in the present study.

\section{Successive liquid-liquid fractionation of the methanol extract}

The methanol extract of Phaleria macrocarpa was fractionated with polarity graded solvents in separating funnels. In brief, $110 \mathrm{~g}$ of the methanol extract was first extracted with $3 \times 360 \mathrm{ml}$ of chloroform-water (6:5). The combined chloroform fractions were dried with anhydrous sodium sulphate and further concentrated in a rotary evaporator. The aqueous layer was extracted with 
$3 \times 250 \mathrm{ml}$ ethyl acetate and the combined ethyl acetate fractions were concentrated as above. Finally, the aqueous layer was extracted with n-butanol $5 \times 250 \mathrm{ml}$ and the combined $n$-butanol fraction was concentrated as well as the remaining aqueous fraction. The concentrated fractions were thereafter freeze-dried to obtain $18 \mathrm{~g}$ (5.45\%), $24.3 \mathrm{~g}$ (7.36\%), $110.1 \mathrm{~g}$ (33.3\%) and $89.1 \mathrm{~g}(27 \%)$ of chloroform (CF), ethyl acetate (EAF), n-butanol (NBF) and aqueous (AF) fractions, respectively. Previous results from the hypoglycaemic and antihyperglycaemic tests with these fractions revealed that the n-butanol fraction was the most effective [14], and hence this alone was selected for the present investigation.

\section{Fractionation of the active $n$-butanol fraction by dry-column flash chromatography}

A chromatographic glass column $(27 \times 5 \mathrm{~cm})$ used in the separation was gently loaded with $100 \mathrm{~g}$ of silica gel (Merck, 7730) in $300 \mathrm{ml}$ petroleum ether. The silica was carefully packed by applying vacuum suction, and a levelled and well-compacted bed yield was ensured. The n-butanol fraction (12 g) was pre-adsorbed onto the adsorbent (silica gel, 200-400 mesh) by first dissolving in methanol $(100 \mathrm{ml})$, followed by addition of the silica gel $(24 \mathrm{~g})$. The mixture was evaporated to dryness using a rotary evaporator, and the resultant dried extract-adsorbent mixture was then loaded onto the top of the already packed column evenly by applying suction. The column was first eluted with $2 \times 300 \mathrm{ml} 100 \%$ chloroform, followed serially by $2 \times 300 \mathrm{ml}$ chloroform-methanol in graded ratios: (9:1), (8:2), (7:3), (6:4), (5:5), (4:6), (3:7), (2:8), (1:9), (0:10) and finally with chloroform-methanol -water (7:13:2). Fractions were collected in a fixed volume and examined with thin layer chromatography using nbutanol-acetic acid-water $(4: 1: 5)$ as the mobile phase. Fractions with similar profiles were pooled together offering two sub-fractions namely SFI and SFII which were freezedried to obtain $20 \mathrm{~g}(40 \%)$ and $8 \mathrm{~g}$ (16\%) respectively. When these sub-fractions were subjected to hypoglycaemic and anti-hyperglycaemic screening, sub-fraction I was found to be the most active [14], therefore it was used for the current $\alpha$-glucosidase and $\alpha$-amylase inhibition tests.

\section{Animals}

Healthy male Sprague Dawley (SD) rats weighing 200$250 \mathrm{~g}$ obtained from the Animal Research and Service Centre, Universiti Sains Malaysia (USM) were used for this study. These were housed in the Animal Transit Room, School of Pharmaceutical Sciences, USM. They were allowed free access to food (standard laboratory chow, Gold Coin Sdn. Bhd., Malaysia) and tap water. The animals were maintained according to accepted international and national guidelines and the procedure for this experiment approved by the Animal Ethics Committee of Universiti Sains Malaysia, Penang, Malaysia (AECUSM). Diabetes was induced in the rats by intraperitoneal injection of $65 \mathrm{mg} / \mathrm{kg}$ b.w. of streptozotocin (Sigma, St Louis, MO, USA), after an overnight fast [15]. Seventy-two (72) hours after, their blood glucose levels were measured using the Accu-check Advantage II Glucose meter (Roche Diagnostics Co., USA) and rats with fasting blood glucose $\geq 15 \mathrm{mmol} / \mathrm{L}$ were considered diabetic and included in the study. The effects of $P$. macrocarpa extract, fraction and sub-fraction on oral carbohydrate tolerance (starch, sucrose and glucose), an indirect measure of $\alpha$-glucosidase and $\alpha$-amylase activities, were evaluated in non-diabetic rats (NDRs) and streptozotocin diabetic rats (SDRs) categorized into groups as shown below. Acarbose, a conventional $\alpha$ glucosidase inhibitor, was used as a positive control in the two sets of experiments.

\section{In vitro a-glucosidase (EC 3.2.1.20) inhibition study}

The assay was performed using our earlier procedure [11]. In brief, $50 \mu \mathrm{l}$ of 4 graded concentrations $(100 \mu \mathrm{g} / \mathrm{ml}$, $50 \mu \mathrm{g} / \mathrm{ml}, 25 \mu \mathrm{g} / \mathrm{ml}, 12.5 \mu \mathrm{g} / \mathrm{ml}$ ) each of sample (extract/ fraction/sub-fraction) and acarbose, the positive control, were suspended in $100 \mu \mathrm{l}$ of $0.1 \mathrm{M}$ phosphate buffer $(\mathrm{pH}$ 6.9) containing yeast $\alpha$-glucosidase (Sigma Aldrich Chemical Co, USA) solution (1.0 U/L) and pre-incubated in a 96-well microplate at $25^{\circ} \mathrm{C}$ for $10 \mathrm{~min}$. After pre-incubation, $50 \mu \mathrm{l}$ of $5 \mathrm{mM}$ p-nitrophenyl- $\alpha$-Dglucopyranoside solution (the enzyme substrate), in $0.1 \mathrm{M}$ phosphate buffer ( $\mathrm{pH}$ 6.9) was added to each well. An equivalent volume $(50 \mu \mathrm{l})$ of buffer solution was added to the blank or control in place of the extract. The reaction mixtures were incubated at $25^{\circ} \mathrm{C}$ for $5 \mathrm{~min}$. The absorbance of the reaction mixtures before and after substrate incubation was measured at $405 \mathrm{~nm}$ on a micro-plate reader (Power Wave Biotek Instrument Inc, USA). The $\alpha$-glucosidase inhibitory activity was calculated from the difference in the two absorbances and expressed as \% inhibition as follows:

$$
\% \text { Inhibition }=\frac{A 540(\text { control })-A 540(\text { extract })}{A 540(\text { control })} \times 100
$$

The experiment was performed in triplicate. The $\mathrm{IC}_{50}$, i.e. the concentration of the extract/fraction/acarbose resulting in 50\% inhibition of the enzyme was calculated by regression analysis.

\section{In vitro a-amylase (EC 3.2.1.1) inhibition study}

A total of $500 \mu \mathrm{l}$ of each sample and $500 \mu \mathrm{l}$ of $0.02 \mathrm{M}$ sodium phosphate buffer ( $\mathrm{pH}$ 6.9) containing porcine $\alpha$ amylase solution $(0.5 \mathrm{mg} / \mathrm{ml})$ were incubated at $25^{\circ} \mathrm{C}$ for $10 \mathrm{~min}$. After pre-incubation, $500 \mu \mathrm{l}$ of $1 \%$ starch 
solution in $20 \mathrm{mM}$ sodium phosphate buffer ( $\mathrm{pH}$ 6.9) was added to each test tube. The reaction mixtures were then incubated at $25^{\circ} \mathrm{C}$ for $10 \mathrm{~min}$ and thereafter stopped by addition of $1 \mathrm{~mL}$ of 3,5-dinitrosalicylic acid (DNS) colour reagent. The test tubes were then incubated in boiling water for $5 \mathrm{~min}$ and then cooled to room temperature. After dilution of the reaction mixtures with $10 \mathrm{ml}$ of distilled water, the absorbance was measured at $540 \mathrm{~nm}$. Acarbose was used as the positive control. The inhibition activity was calculated as follows:

$$
\% \text { Inhibition }=\frac{A 540(\text { control })-A 540(\text { extract })}{A 540(\text { control })} \times 100
$$

Control incubations representing 100\% enzyme activity were carried out in a similar fashion by replacing the plant extract/fraction with vehicle $(500 \mu \mathrm{l}$ DMSO and distilled water). For the blank incubation, the enzyme solution was replaced with distilled water and the same procedure was followed as above. Separate incubations conducted for the reaction of $\mathrm{t}=0 \mathrm{~min}$ was performed by adding samples to the DNS solution immediately after addition of the enzyme. The experiment was also performed in triplicate and the $\mathrm{IC}_{50}$, i.e. the concentration of the extract/fraction/acarbose resulting in 50\% inhibition of the enzyme was calculated by regression analysis.

\section{Confirmatory in vivo studies in non-diabetic rats (NDRs) Starch tolerance test}

In this test, 30 overnight-fasted non-diabetic rats divided into five groups of six each were respectively treated (p.o.) with ME (1 g/kg), NBF (1 g/kg), SFI (1 g/kg), acarbose (positive control, $10 \mathrm{mg} / \mathrm{kg}$ ), and distilled water (negative control). Ten minutes after, the rats were administered starch ( $3 \mathrm{~g} / \mathrm{kg}$ body weight) orally and blood was collected via tail puncture for blood glucose estimation before (0 min) and at 30, 60 and 120 minutes after starch treatment [16]. The recorded blood glucose concentrations peak blood glucose (PBG) and area under curve (AUC) were determined. Whereas the maximum blood glucose concentration for each group was taken as PBG for the group, AUC was calculated using the relationship:

$$
\begin{aligned}
\operatorname{AUC}(\mathrm{mmol} / \mathrm{L} \cdot \mathrm{h})= & \frac{\mathrm{BG}_{0}+\mathrm{BG}_{30} \times 0.5}{2} \\
& +\frac{\mathrm{BG}_{30}+\mathrm{BG}_{60 \times 0.5}}{2} \\
& +\frac{\mathrm{BG}_{60}+\mathrm{BG}_{120 \times 1}}{2}
\end{aligned}
$$

Where BG represents the blood glucose concentration measured at time intervals 0, 30, 60 and 120 minutes.

\section{Sucrose tolerance test}

The sucrose tolerance test was carried out using the same procedure as for the determination of starch tolerance. However, in this test, sucrose at a dose of $4 \mathrm{~g} / \mathrm{kg}$ body weight was used instead of starch.

\section{Glucose tolerance test}

The oral glucose tolerance test was also carried out using the same procedure as for the determination of starch tolerance, but glucose at a dose of $2 \mathrm{~g} / \mathrm{kg}$ body weight was used instead of starch.

\section{Confirmatory in vivo tests using streptozotocin-induced diabetic rats (SDRs)}

This second set of tests also evaluated the effects of the active methanol extract (ME), fraction (NBF) and subfraction (SFI) on the tolerance of diabetic rats to orally administered starch, sucrose or glucose. In each test, 5 groups of rats $(n=6)$ were treated as follows. Groups 1-3 were treated with $1 \mathrm{~g} / \mathrm{kg}$ each of ME, NBF and SFI, respectively and groups 4 (positive control) and 5 (negative control) were treated with acarbose $(10 \mathrm{mg} / \mathrm{kg})$ and an equivalent volume of distilled water (p.o.), respectively. As in earlier tests, 10 minutes after oral starch $(3 \mathrm{~g} / \mathrm{kg}) /$ sucrose $(4 \mathrm{~g} / \mathrm{kg}) /$ glucose $(2 \mathrm{~g} / \mathrm{kg})$ treatment, blood glucose was measured at 0, 30, 60 and $120 \mathrm{~min}$ and used for PBG and AUC determinations similar as described above.

\section{Statistical analysis}

Data are expressed as mean \pm SEM. Analysis of variance (ANOVA) followed by post hoc analysis (Dunnett's test) were used for data analysis using the SPSS statistical package, version 17.0. Differences at $P<0.05$ were considered significant.

\section{Results}

\section{In vitro inhibition of a-glucosidase activity}

The methanol extract (ME), n-butanol fraction (NBF) and sub-fraction 1 (SFI) of $P$. macrocarpa potently inhibited $\alpha$-glucosidase activity in vitro in a dosedependent manner (Figure 1). At the highest concentration $(100 \mu \mathrm{g} / \mathrm{ml})$, NBF showed the highest percentage $\alpha$-glucosidase inhibition of about $75 \%$. This was $20 \%$ higher than that of acarbose (55\%), a standard $\alpha$-glucosidase inhibitor. The corresponding maximum inhibitory activities of the ME and SFI at the same concentrations were $32 \%$ and $20 \%$ respectively. This relative $\alpha$-glucosidase inhibition was clearly indicated by the $\mathrm{IC}_{50}$ values (the concentration required for $50 \%$ inhibition) of each test analyte (Table 1 ). NBF with the highest inhibitory activity has lowest $\mathrm{IC}_{50}$ of $2.40 \pm 0.23 \mu \mathrm{g} / \mathrm{ml}$, closely followed by acarbose $(3.40 \pm 0.19 \mu \mathrm{g} / \mathrm{ml})$. The methanol extract and SFI had $\mathrm{IC}_{50}$ values of $7.50 \pm 0.15 \mu \mathrm{g} / \mathrm{ml}$ and $11.45 \pm$ $0.28 \mu \mathrm{g} / \mathrm{ml}$ respectively. 


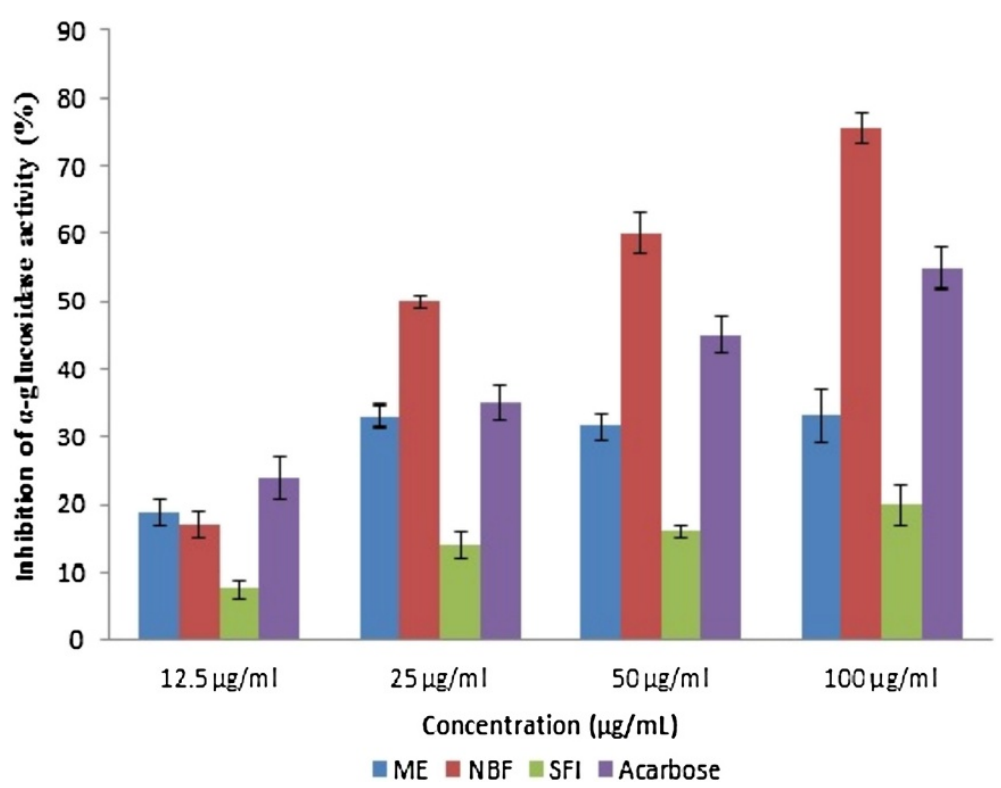

Figure 1 Inhibitory effect of extract/fractions of $P$. macrocarpa fruit pericarp and acarbose on yeast a-glucosidase activity. The test was performed in triplicate; values (\% enzyme activity) are the mean \pm SEM. ME: Methanol extract, NBF: n-Butanol fraction, SFI: Sub-fraction 1.

\section{In vitro inhibition of a-amylase activity}

Figure 2 shows the \% inhibition of $\alpha$-amylase activity by ME, NBF and SFI along with the effect of acarbose. The standard drug, acarbose exerted the most potent inhibitory action against $\alpha$-amylase of about $90 \%$ at $100 \mu \mathrm{g} /$ $\mathrm{ml}$. The inhibition by the extract and fractions were dependent on the concentrations/dose used. The methanol extract and NBF exerted similar peak inhibition activity of $87 \%$ while SFI inhibited $\alpha$-amylase by $67 \%$ at the highest concentration used $(100 \mu \mathrm{g} / \mathrm{ml})$. The inhibition pattern also followed suit at lower concentrations.

\section{Effect of treatments on glucose tolerance tests in non- diabetic and diabetic rats}

Table 2 and Figures 3 and 4 show the effect of ME, NBF and SFI of $P$. macrocarpa on glucose tolerance in NDRs and SDRs. All treatments reduced the PBG in NDRs 30 minutes after oral glucose load, but only the reductions caused by SFI (30.34\%) and acarbose (26.97\%) were

Table 1 IC 50 values for yeast a-glucosidase and a-amylase inhibition

\begin{tabular}{lll}
\hline Analyte & \multicolumn{2}{l}{ Inhibitory concentration, $\mathbf{I C}_{\mathbf{5 0}}(\boldsymbol{\mu g} \mathbf{g} \mathbf{m} \mathbf{l})$} \\
\cline { 2 - 3 } & a-glucosidase & a-amylase \\
\hline Methanol extract (ME) & $7.50 \pm 0.15$ & $43.9 \pm 0.19$ \\
n-butanol fraction (NBF) & $2.40 \pm 0.23$ & $58.5 \pm 0.13$ \\
Sub-fraction I (SFI) & $11.45 \pm 0.28$ & $69.8 \pm 0.25$ \\
Acarbose (ACAR) & $3.40 \pm 0.19$ & $32.0 \pm 0.30$ \\
\hline
\end{tabular}

significant compared with the NCs. There was also a corresponding significant decrease of AUC in the 4 treatment groups compared with the control $(P<0.05)$, implying an onward flattening of the glucose tolerance curves (Figure 3). In the SDRs, the ME failed to exert any observable effect on the tolerance level following oral glucose loading. The NBF and SFI showed nonsignificant decreases in PBG levels (2.69\% and 9.44\%) and AUCs (7.21 and 13.40\%) respectively. The control compound acarbose exerted a significant reduction of the PBG level (20.76\%) and AUC (31.20\%) in line with its known in vivo $\alpha$-amylase inhibitory action.

\section{Effect of treatment on sucrose tolerance tests in non- diabetic and diabetic rats}

The effects of $P$. macrocarpa extracts/fractions and acarbose on sucrose tolerance in NDRs and SDRs are shown in Table 3 and Figures 5 and 6. From the test results in NDRs, SFI alone demonstrated a strong inhibitory action against $\alpha$-glucosidase in vivo, i.e. $17.28 \%$ and 15.57\% reductions in PBG and AUC respectively, similar to the effect of acarbose $(24.76 \%$ and $21.63 \% ; P<0.05)$. The ME and NBF showed weak activity against the enzyme in vivo. Results of the tolerance test in SDR revealed that NBF was the most effective at inhibiting $\alpha$ glucosidase action in vivo i.e. $15.08 \%$ and $14.23 \%$ reductions in PBG and AUC respectively $(P<0.05)$. The in vivo inhibition corresponds to its high inhibitory activity observed in the in vitro $\alpha$-glucosidase test. Although SFI was weak in reducing the PBG within the 


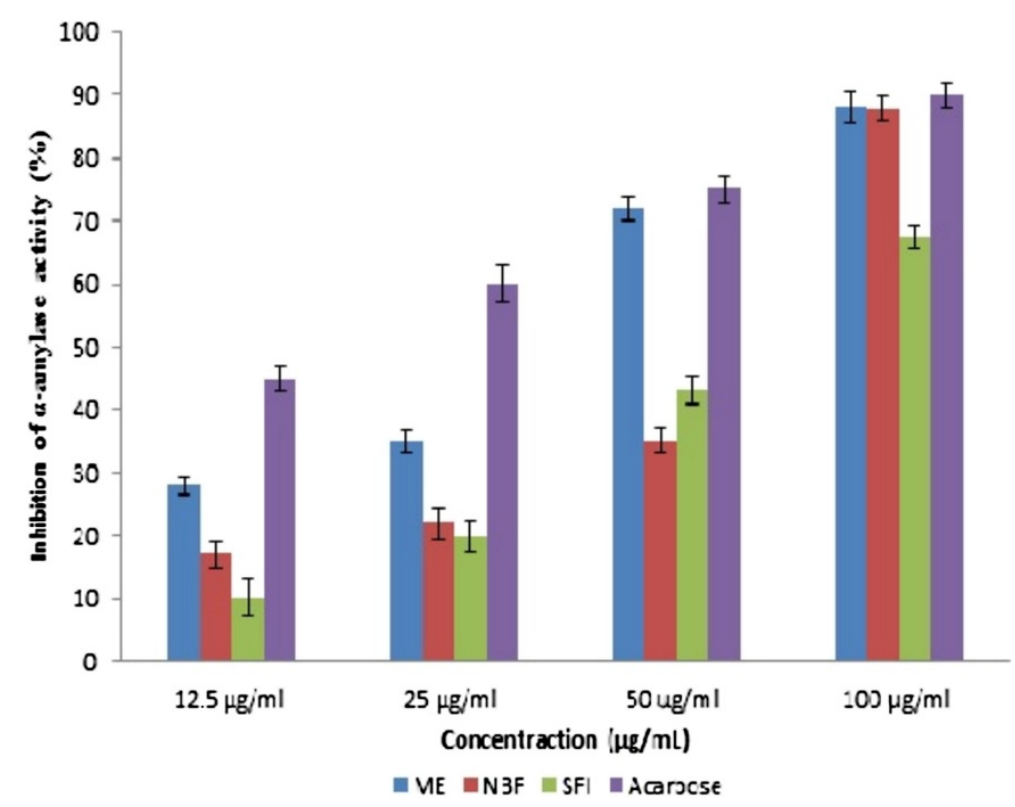

Figure 2 Inhibitory effects of extract/fractions of $P$. macrocarpa fruit pericarp and acarbose on porcine a-amylase activity. The test was performed in triplicate; values (\% enzyme activity) are the mean \pm SEM. ME: Methanol extract, NBF: n-Butanol fraction, SFI: Sub-fraction 1.

first 30 minutes, it effectively attenuated the tolerance curve over the 2 hours by $12.46 \%(P<0.05)$. Acarbose was potent at reducing the PBG level $(23.36 \%)$ and AUC (31.55\%) significantly $(P<0.05)$.

\section{Effect of treatments on starch tolerance tests in non-}

diabetic and diabetic rats

In NDRs, both PBG and AUC were reduced by the 4 treatments (Table 4 and Figure 7). However, the reduction in PBG level was only significant in NBF and acarbose PBG treated groups and for the AUC in the acarbose treated group $(P<0.05)$. In SDRs, NBF and SFI decreased PBG and AUC non-significantly compared with the DC, whereas ME had no effect on the tolerance curve (Figure 8).

\section{Discussion}

$\alpha$-Glucosidase inhibitors, a group of oral hypoglycaemic agents (OHA), have proven more useful and beneficial than other anti-diabetic drugs due to their exceptional

Table 2 Effect of treatments on blood glucose (PBG) and area under the curve (AUC) after glucose loading (4 g/kg) in non-diabetic rats (NDRs) and STZ-diabetic rats (SDRs)

\begin{tabular}{|c|c|c|c|c|}
\hline Group & PBG (mmol/L) & $\%$ Reduction of PBG & AUC (mmol/L) & $\%$ Reduction of $A \cup C$ \\
\hline \multicolumn{5}{|l|}{ Non-diabetic rats } \\
\hline NC (vehicle) & $8.9 \pm 0.34$ & & $14.4 \pm 0.32$ & \\
\hline ACAR (10 mg/kg) & $6.5 \pm 0.32^{*}$ & 26.97 & $11.2 \pm 0.44^{*}$ & 22.22 \\
\hline ME (1 g/kg) & $7.4 \pm 0.31$ & 16.85 & $12.4 \pm 0.48^{*}$ & 13.89 \\
\hline NBF $(1 \mathrm{~g} / \mathrm{kg})$ & $7.15 \pm 0.18$ & 19.66 & $12.08 \pm 0.28^{*}$ & 16.11 \\
\hline $\mathrm{SFI}(1 \mathrm{~g} / \mathrm{kg})$ & $6.20 \pm 0.15^{*}$ & 30.34 & $11.04 \pm 0.09^{*}$ & 23.33 \\
\hline \multicolumn{5}{|l|}{ Diabetic rats } \\
\hline DC (vehicle) & $21.92 \pm 0.8$ & & $39.93 \pm 1.75$ & \\
\hline ACAR $(10 \mathrm{mg} / \mathrm{kg})$ & $17.37 \pm 0.66^{*}$ & 20.76 & $27.47 \pm 0.9^{*}$ & 31.20 \\
\hline ME (1 g/kg) & $22.05 \pm 0.53$ & - & $40.08 \pm 0.74$ & - \\
\hline NBF $(1 \mathrm{~g} / \mathrm{kg})$ & $21.33 \pm 1.22$ & 2.69 & $37.05 \pm 1.6$ & 7.21 \\
\hline SFI (1 g/kg) & $19.85 \pm 1.42$ & 9.44 & $34.58 \pm 2.34$ & 13.40 \\
\hline
\end{tabular}

Values are the mean $\pm \mathrm{SEM}, \mathrm{n}=6,{ }^{*} P<0.05$ vs. control. NC: Normal control, $D C$ : Diabetic control, ACAR: Acarbose, ME: Methanol extract, NBF: $\mathrm{n}$-Butanol fraction, SFI: Sub-fraction 1. 


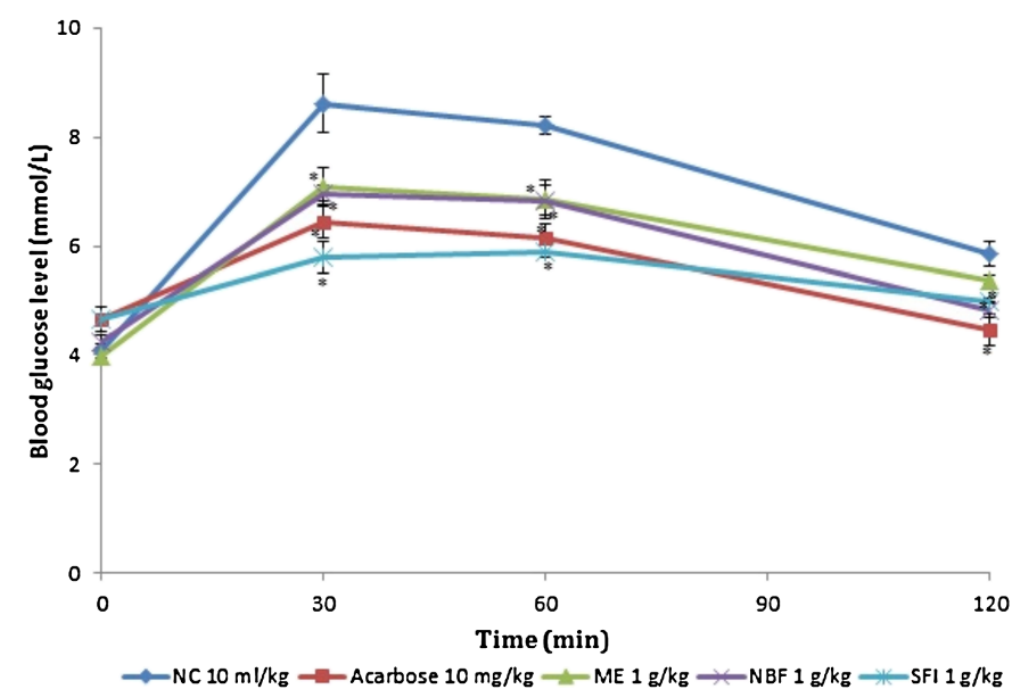

Figure 3 Effects of treatments on glucose tolerance after oral glucose administration $(2 \mathrm{~g} / \mathbf{k g})$ in non-diabetic rats (NDRs). Values are the mean \pm SEM $(n=6)$, ${ }^{*} P<0.05$ vs. control. NC: Normal control, ACAR: Acarbose, ME: Methanol extract, NBF: $n$-Butanol fraction, SFl: Sub-fraction 1.

benefits for management of post prandial hyperglycaemia $(\mathrm{PPH})$. In terms of blood glucose lowering action, the $\alpha$ glucosidase inhibitors are less effective compared with most other OHAs. Their singular advantage of averting the risk of $\mathrm{PPH}$ has made them most suitable in combination with other agents [17]. Therefore, the in vitro and in vivo $\alpha$-glucosidase and $\alpha$-amylase inhibitory effect of $P$. macrocarpa, a plant with evidence of strong empirical anti-diabetic properties, was investigated.
To our knowledge, the present study demonstrates for the first time the potent inhibitory activity of $P$. macrocarpa fruit extract and fractions against $\alpha$-glucosidase and $\alpha$-amylase in vitro. The $\mathrm{n}$-butanol fraction had the highest inhibitory action against the two enzymes relative to the methanol extract and the sub-fraction. This effective inhibitory action of the n-butanol fraction can be correlated to its high mangiferin composition. An earlier LC-MS analysis of the three analytes revealed that

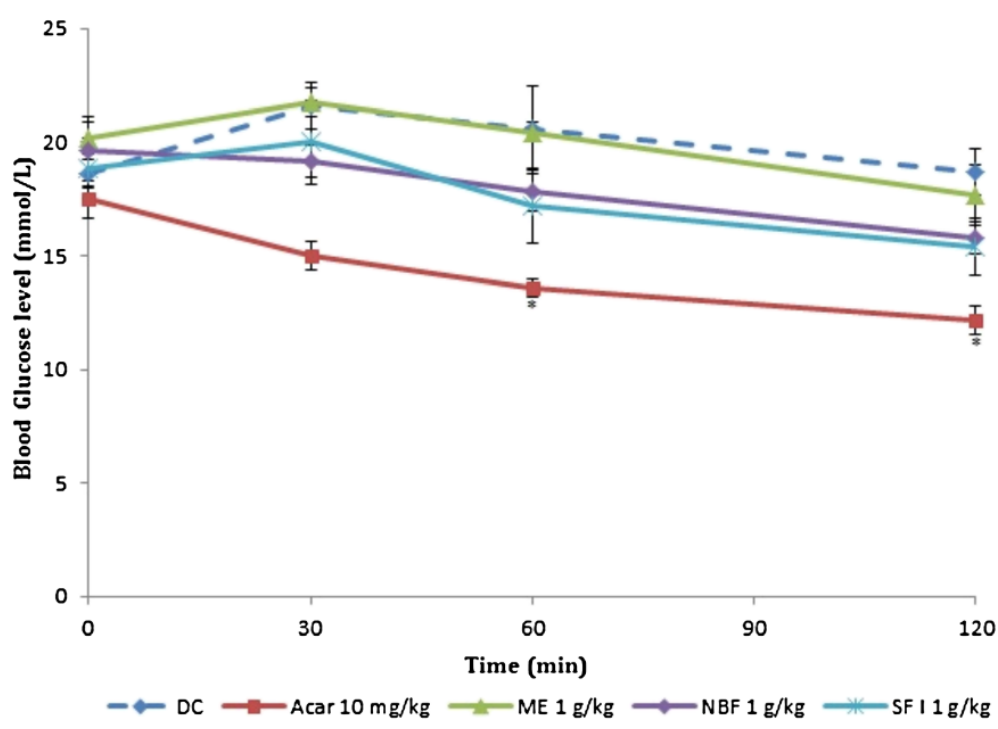

Figure 4 Effect of treatments on glucose tolerance after oral glucose administration $(2 \mathrm{~g} / \mathrm{kg})$ in streptozotocin-induced diabetic rats (SDRs). Values are the mean \pm SEM $(n=6) * P<0.05$ vs. control. DC: Diabetic control, ACAR: Acarbose, ME: Methanol extract, NBF: $n-B u t a n o l$ fraction, SFl: Sub-fraction 1. 
Table 3 Effect of treatments on peak blood glucose (PBG) and area under the curve (AUC) after sucrose loading (4 $\mathrm{g} / \mathrm{kg}$ ) in non-diabetic rats (NDRs) and STZ-diabetic rats (SDRs)

\begin{tabular}{|c|c|c|c|c|}
\hline Group & PBG (mmol/L) & $\%$ Reduction of PBG & AUC (mmol/L) & $\%$ Reduction of AUC \\
\hline \multicolumn{5}{|l|}{ Non-diabetic rats } \\
\hline NC (vehicle) & $7.35 \pm 0.41$ & & $13.04 \pm 0.54$ & \\
\hline ACAR $(10 \mathrm{mg} / \mathrm{kg})$ & $5.53 \pm 0.14^{*}$ & 24.76 & $10.22 \pm 0.19^{*}$ & 21.63 \\
\hline ME (1 g/kg) & $6.30 \pm 0.10$ & 14.29 & $11.46 \pm 0.18$ & 12.12 \\
\hline NBF $(1 \mathrm{~g} / \mathrm{kg})$ & $6.52 \pm 0.18$ & 11.29 & $11.65 \pm 0.28$ & 10.66 \\
\hline $\mathrm{SFI}(1 \mathrm{~g} / \mathrm{kg})$ & $6.08 \pm 0.14$ & 17.28 & $11.01 \pm 0.20^{*}$ & 15.57 \\
\hline \multicolumn{5}{|l|}{ Diabetic rats } \\
\hline DC (vehicle) & $24.14 \pm 1.14$ & & $43.71 \pm 1.10$ & \\
\hline ACAR $(10 \mathrm{mg} / \mathrm{kg})$ & $18.5 \pm 0.96^{*}$ & 23.36 & $29.92 \pm 0.78^{*}$ & 31.55 \\
\hline ME (1 g/kg) & $21.5 \pm 1.10$ & 10.94 & $40.97 \pm 1.66$ & 6.27 \\
\hline NBF $(1 \mathrm{~g} / \mathrm{kg})$ & $20.53 \pm 0.9$ & 15.08 & $37.49 \pm 1.45^{*}$ & 14.23 \\
\hline $\mathrm{SFI}(1 \mathrm{~g} / \mathrm{kg})$ & $22.58 \pm 1.45$ & 6.46 & $38.27 \pm 1.68^{*}$ & 12.46 \\
\hline
\end{tabular}

Values are the mean $\pm \mathrm{SEM}, \mathrm{n}=6,{ }^{*} P<0.05$ vs. control. NC: Normal control, DC: Diabetic control, ACAR: Acarbose, ME: Methanol extract, NBF: $\mathrm{n}-\mathrm{Butanol}$ fraction, SFI: Sub-fraction 1.

mangiferin, a compound previously isolated from this plant, was the predominant bio-compound in P. macrocarpa, occurring at $9.52 \%$ in the methanol extract, $33.30 \%$ in the n-butanol fraction and $22.50 \%$ in the sub-fraction 1 [14]. Moreover, previously, mangiferin isolated from Salacia species, Mangifera indica and Belamcanda chinensis was also shown to exhibit strong inhibitory activities against $\alpha$ glucosidase in vitro [18-20]. Additionally, the antidiabetic effect of mangiferin in streptozotocin-induced diabetic rats has been reported $[21,22]$. The involvement of mangiferin in the enzyme inhibition was also supported by the fact that the sub-fraction with the second highest content of mangiferin exerted the second highest inhibitory activity. Contrary to the expected result from activity-guided assays, the mangiferin content was found to be lower in SFI, the purer fraction, than NBF. The method required for processing, including the use of flash column and thin layer chromatography and treatment with several solvents, may have resulted in the degradation of mangiferin, accounting for its relatively low content and detection in the LC-MS assay.

The observed in vitro $\alpha$-glucosidase and $\alpha$-amylase inhibitory effects were replicated in the in vivo carbohydrate tolerance tests for the most part. The n-butanol

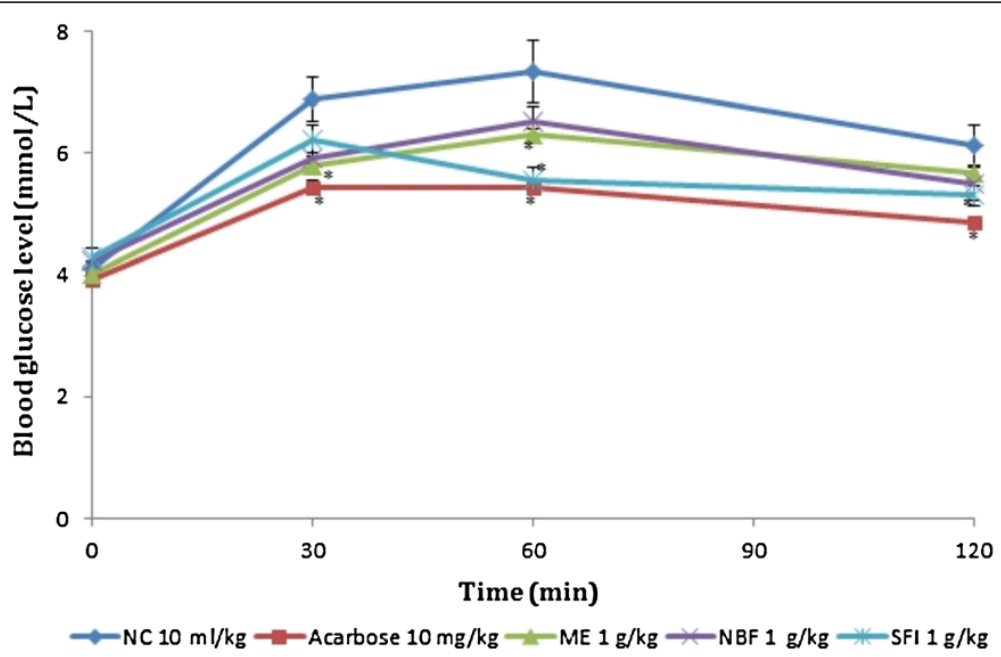

Figure 5 Effect of treatments on sucrose tolerance after oral sucrose administration $(\mathbf{4} \mathbf{g} / \mathbf{k g})$ in non-diabetic rats (NDRs). Values are the mean \pm SEM $(n=6)$, ${ }^{*} P<0.05$ vs. control. NC: Normal control, ACAR: Acarbose, ME: Methanol extract, NBF: $n$-Butanol fraction, SFl: Sub-fraction 1. 


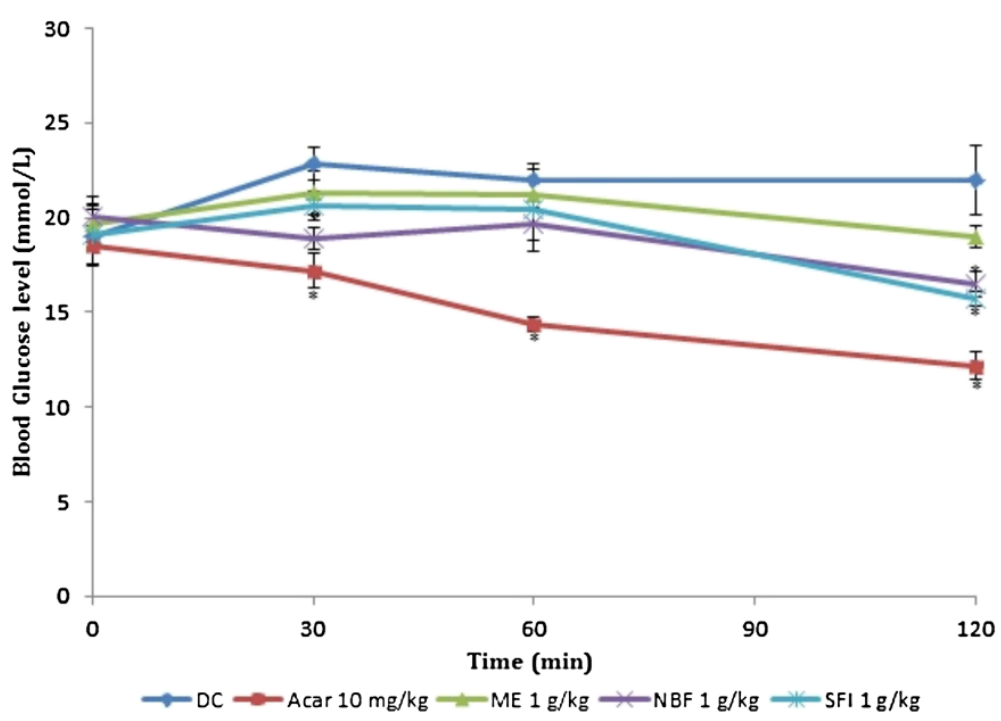

Figure 6 Effect of treatments on sucrose tolerance after oral sucrose administration $(4 \mathrm{~g} / \mathrm{kg})$ in streptozotocin-induced diabetic rats (SDRs). Values are the mean \pm SEM $(n=6),{ }^{*} P<0.05$ vs. control. DC: Diabetic control, ACAR: Acarbose, ME: Methanol extract, NBF: $n$-Butanol fraction, SFI: Sub-fraction 1.

fraction and sub-fraction 1 significantly reduced the AUC in streptozotocin-treated diabetic rats after oral sucrose administration. The extent of the reduction also corresponded to the mangiferin composition. A similar observation from a glucose tolerance test with extracts from young and old leaves and fruits of $P$. macrocarpa conducted in non-diabetic animals was reported by Sugiwati and co-workers $[9,10]$. Natural products with properties such as those identified in this study have the capacity to delay carbohydrate absorption into the blood stream by reversibly inhibiting the activity of carbohydrate digesting enzymes in the small intestinal brush border that are responsible for the breakdown of oligosaccharides and disaccharides into monosaccharides suitable for absorption [23]. Alternatively, some natural products may function by simply delaying the transfer of glucose from the stomach to the small intestine, the main site of glucose absorption (delayed gastric emptying rate) [24,25].

Table 4 Effect of treatments on peak blood glucose (PBG) and area under the curve (AUC) after starch loading (4 g/kg) in non-diabetic rats (NDRs) and STZ-diabetic rats (SDRs)

\begin{tabular}{|c|c|c|c|c|}
\hline Group & PBG (mmol/L) & $\%$ Reduction of PBG & AUC (mmol/L) & $\%$ Reduction of AUC \\
\hline \multicolumn{5}{|l|}{ Non-diabetic rats } \\
\hline NC (vehicle) & $6.12 \pm 0.10$ & & $11.22 \pm 0.17$ & \\
\hline ACAR $(10 \mathrm{mg} / \mathrm{kg})$ & $4.43 \pm 0.11^{*}$ & 27.61 & $9.10 \pm 0.19^{*}$ & 18.89 \\
\hline ME (1 g/kg) & $5.78 \pm 0.39$ & 5.56 & $10.37 \pm 0.50$ & 7.58 \\
\hline NBF $(1 \mathrm{~g} / \mathrm{kg})$ & $5.18 \pm 0.08^{*}$ & 15.36 & $9.61 \pm 0.08$ & 14.35 \\
\hline SFI (1 g/kg) & $5.97 \pm 0.05$ & 2.45 & $10.58 \pm 0.15$ & 5.70 \\
\hline \multicolumn{5}{|l|}{ Diabetic rats } \\
\hline DC (vehicle) & $22.5 \pm 1.02$ & & $41.2 \pm 1.74$ & \\
\hline ACAR $(10 \mathrm{mg} / \mathrm{kg})$ & $18.7 \pm 1.95$ & 16.89 & $26.1 \pm 2.8^{*}$ & 36.65 \\
\hline ME (1 g/kg) & $22.6 \pm 1.03$ & - & $43.9 \pm 2.99$ & - \\
\hline NBF $(1 \mathrm{~g} / \mathrm{kg})$ & $21.1 \pm 1.38$ & 6.22 & $35.6 \pm 2.32$ & 13.59 \\
\hline SFI (1 g/kg) & $19.1 \pm 1.00$ & 15.11 & $33.5 \pm 1.5$ & 18.69 \\
\hline
\end{tabular}

Values are the mean $\pm \mathrm{SEM}, \mathrm{n}=6,{ }^{*} P<0.05$ vs. control. NC: Normal control, $D C$ : Diabetic control, ACAR: Acarbose, ME: Methanol extract, NBF: $\mathrm{n}$-Butanol fraction, SFI: Sub-fraction 1 . 


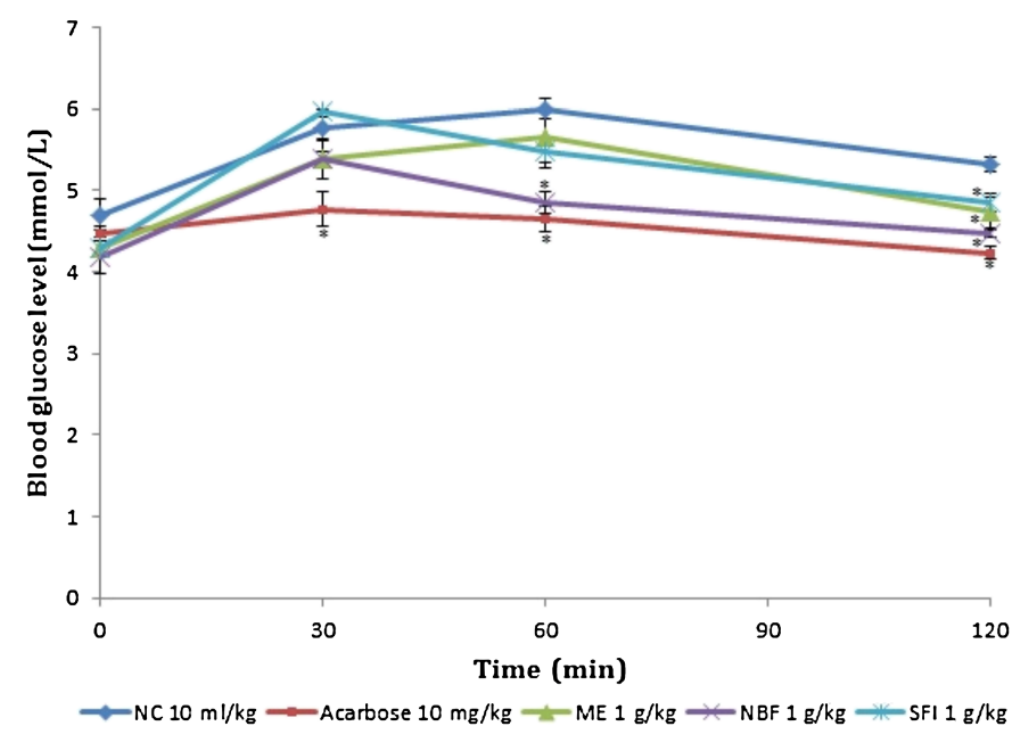

Figure 7 Effect of treatments on starch tolerance after oral starch administration $(3 \mathbf{g} / \mathbf{k g}$ ) in non-diabetic rats (NDRs). Values are the mean \pm SEM $(n=6),{ }^{*} P<0.05$ vs. control. NC: Normal control, ACAR: Acarbose, ME: Methanol extract, NBF: $n$-Butanol fraction, SFI: Sub-fraction 1.

Consequently, these natural products avert the threat of hyperglycaemia after meals, and more importantly may provide glycaemic control without hyperinsulinaemia and body weight gain. Agents including conventional drugs that exploit any of the two targets to exert their anti-diabetic action are of particular interest for the management and prevention of type II diabetes mellitus.

\section{Conclusions}

P. macrocarpa is a traditional medicinal plant with a long history of use as an anti-diabetic remedy in Asia Pacific countries. The present study, besides contributing to the scientific validation of the anti-diabetic properties of $P$. macrocarpa, suggests that attenuation of carbohydrate hydrolysis via inhibition of $\alpha$-glucosidase and $\alpha$-amylase activities is one mechanism of its hypoglycaemic and anti-

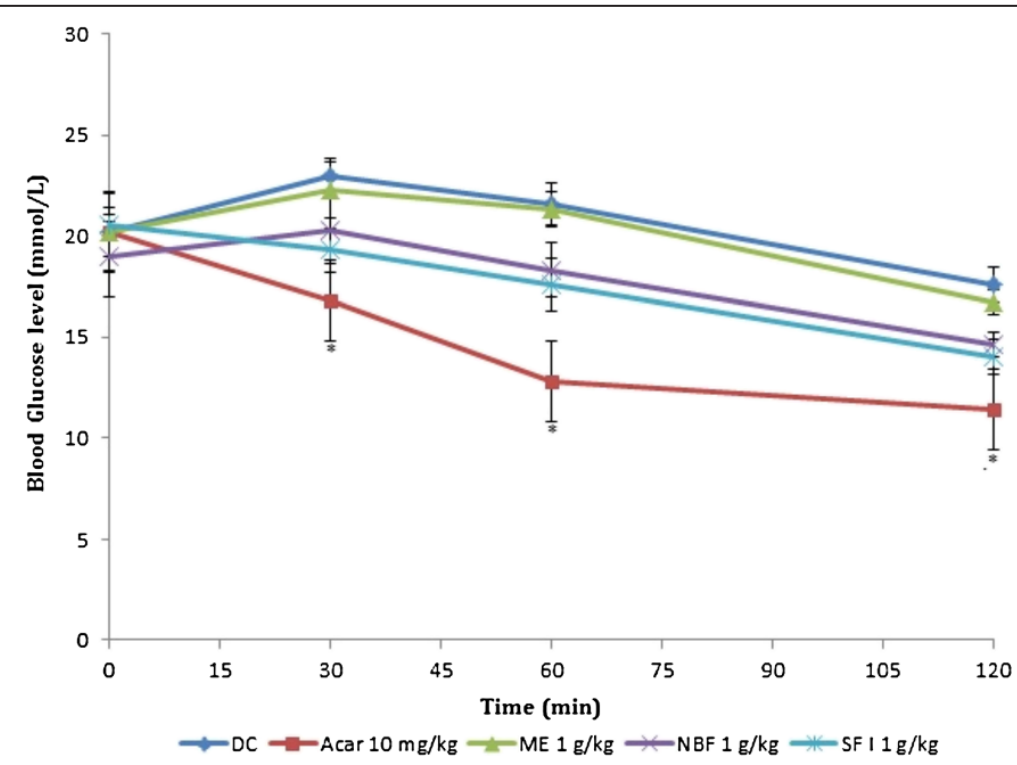

Figure 8 Effect of treatments on starch tolerance after oral starch administration $(3 \mathrm{~g} / \mathrm{kg})$ in streptozotocin-induced diabetic rats (SDRs). Values are the mean \pm SEM $(n=6),{ }^{*} P<0.05$ vs. control. DC: Diabetic control, ACAR: Acarbose, ME: Methanol extract, NBF: $n-B u t a n o l$ fraction, SFl: Sub-fraction 1. 
hyperglycaemic therapeutic benefits. Moreover, mangiferin, a compound previously isolated from this plant may be responsible for the observed enzyme inhibition activity. Hence, $P$. macrocarpa is a prospective and veritable source of natural products for the management of type II diabetes mellitus.

\section{Competing interests}

The authors declare that they have no competing interests.

\section{Authors' contributions}

RBA and NK carried out the animal experiments as part of their postgraduate research work. IJA and MA directed the experiments, articulated the results and drafted the manuscript. MZA and RM conceived the study, and participated in its design and coordination and helped to proof the draft manuscript. All authors read and approved the final manuscript.

\section{Acknowledgements}

This work was financially supported by an RU Grant from Universiti Sains Malysia (1001/PFARMASI/815080). Dr. Item Justin Atangwho is a TWAS-USM (the Academy of Science for the Developing World - Universiti Sains Malaysia) Postdoctoral Fellow at the School of Pharmaceutical Sciences, Universiti Sains Malaysia, Penang, Malaysia.

Received: 2 October 2012 Accepted: 11 February 2013 Published: 20 February 2013

\section{References}

1. Grover JK, Yadav S, Vats V: Medicinal plants of India with anti-diabetic potential. J Ethnopharmacol 2002, 81:81-100.

2. Samy RP, Gopalakrishnakone P: Current status of herbals and their future perspective. Nature Proceedings, [http://hdl.handle.net/10101/npre.2007.1176.1]

3. Houghton PJ: Synergy and polyvalence: paradigm to explain the activity of herbal products. In Evaluation of herbal medicinal products. Edited by Houghton PJ, Mukherjee PK. London: Pharmaceutical press; 2009:85-94.

4. Shaw JE, Sicree RA, Zimmet PZ: Global estimates of the prevalence of diabetes for 2010 and 2030. Diabet Res Clin Pract 2010, 87:4-1 4.

5. Jelodar G, Maleki M, Sirus S: Effect of Walnut leaf, Coriader and Pomegranate on blood glucose and histopathology of pancreas of alloxan induced diabetic rats. Afr J Trad Compl Altern Med 2007, 4:299-305.

6. Tjandrawinata RR, Arifin PF, Tandrasasmita OM, Rahmi D, Aripin A: DLBS 1425, a Phaleria macrocarpa (Scheff.) Boerl. extract confers antiproliferative and pro-apoptosis effects via eicosanoid pathway. J Exp Ther Oncol 2010, 8:187-201.

7. Triastuti A, Choi JW: Protective effects of ethyl acetate fraction of Phaleria macrocarpa (Scheff) Boerl. on oxidative stress associatedwith alloxaninduced diabetic rats. Jurnal IImiah Farmasi 2008, 5:9-17.

8. Triastuti A, Park H-J, Choi JW: Phaleria macrocarpa suppress nephropathy by increasing renal antioxidant enzyme activity in alloxan-induced diabetic rats. Nat Prod Sci 2009, 15:167-172.

9. Sugiwati S, Kardono LBS, Bintang M: a-Glucosidase inhibitory activity and hypoglycaemic effect of Phaleria marcrocapa fruit pericarp extracts by oral administration to rats. J App/ Sci 2006, 6:2312-2316.

10. Sugiwati S, Setiasih S, Afifah DE: Antihyperglycaemic activity of the mahkota Dewa [Phaleria macrocarpa (scheff.) boerl.] leaf extracts as an alpha-glucosidase inhibitor. Makara Kesehatan 2009, 13:74-78.

11. Subramanian R, Asmawi MZ, Sadikun A: In vitro a-glucosidase and aamylase enzyme inhibitory effects of Andrographis paniculata extract and andrographolides. Acta Biochemica Polonica 2008, 55:391-398.

12. Ye F, Shen Z, Xie M: Alpha-glucosidase inhibition from a Chinese medical herb (Ramulus mori) in normal and diabetic rats and mice. Phytomed 2002, 9:161-166.

13. Ali RB, Atangwho IJ, Kuar N, Mohamed EAH, Mohamed AJ, Asmawi MZ, Mahmud R: Hypoglycaemic and anti-hyperglycaemic study of Phaleria macrocarpa fruits pericarp. J Med Plants Res 2012, 6(10):1982-1990.

14. Ali RB, Atangwho IJ, Kaur N, Abraika OS, Ahmad M, Mahmud R, Asmawi MZ: Bioassay-guided anti-diabetic study of Phaleria macrocarpa fruit extract. Molecules 2012, 17:4986-5002.

15. Atangwho IJ, Ebong PE, Eyong EU, Asmawi MZ, Ahmad M: Synergistic antidiabetic activity of Vernonia amygdalina and Azadirachta indica:
Biochemical effects and possible mechanism. J Ethnopharmacol 2012, 141:878-887.

16. Subramanian R, Asmawi MZ: Inhibition of a-glucosidase by Andrographis paniculata ethanol extract in rats. Pharmaceut Chem 2006, 44:600-606.

17. American Diabetes Association: Expert committee clinical practice guidelines for the prevention and management of diabetes. Diabetes 2003, 27(Suppl):S1-S152.

18. Yoshikawa M, Nishida N, Shimoda H, Takada M, Kawahara Y, Matsuda H: Polyphenol constituents from salacia species: quantitative analysis of mangiferin with a-glucosidase and aldose reductase inhibitory activities. Yakugaku Zasshi 2001, 121:371-378.

19. Dineshkumar B, Mitra A, Manjunatha M: Studies on the anti-diabetic and hypolipidemic potentials of mangiferin (xanthone glucoside) in streptozotocin-induced Type 1 and Type 2 diabetic model rats. Int J Adv Pharmaceut Sci 2010, 1:75-85.

20. Wu C, Shen J, He P, Chen Y, Li L, Zhang L, Li Y, Fu Y, Dai R, Meng W, Deng $Y$ : The a-glucosidase inhibiting isoflavones isolated from Belamcanda chinensis leaf extract. Rec Nat Prod 2012, 6:110-120.

21. Muruganandan S, Srinivasan K, Gupta S, Gupta PK, Lala L: Effect of mangiferin on hyperglycemia and atherogenicity in streptozotocin diabetic rats. J Ethnopharmacol 2005, 97:497-501.

22. Sellamuthu PS, Muniappan BP, Perusal SM, Kandasamy M: Antihyperglycemic effect of mangiferin in streptozotocin induced diabetic rats. J Health Sci 2009, 55:206-214.

23. Lebovitz HE: Alpha-glucosidase inhibitors. Endocrinol Metab Clin North Am 1997, 26:539-551.

24. Shane-McWhorter L: Biological complementarytherapies: a focus on botanical products in diabetes. Diabet Spect 2001, 14:199-208.

25. Yeh GY, Eisenberg DM, Kaptcuk TJ, Philips RS: System review of herbs and dietary supplements for glycemic control in diabetes. Diabet Care 2003, 26:1277-1294

doi:10.1186/1472-6882-13-39

Cite this article as: Ali et al:: In vitro and in vivo effects of standardized extract and fractions of Phaleria macrocarpa fruits pericarp on lead carbohydrate digesting enzymes. BMC Complementary and Alternative Medicine 2013 13:39.

\section{Submit your next manuscript to BioMed Central and take full advantage of:}

- Convenient online submission

- Thorough peer review

- No space constraints or color figure charges

- Immediate publication on acceptance

- Inclusion in PubMed, CAS, Scopus and Google Scholar

- Research which is freely available for redistribution 